This item was submitted to Loughborough's Research Repository by the author.

Items in Figshare are protected by copyright, with all rights reserved, unless otherwise indicated.

\title{
An impedance model for analysis of EIS of polymer electrolyte fuel cells under hydrogen peroxide formation in the cathode
}

PLEASE CITE THE PUBLISHED VERSION

http://dx.doi.org/10.1016/j.jelechem.2015.03.012

\section{PUBLISHER}

(C) Elsevier B.V.

\section{VERSION}

AM (Accepted Manuscript)

\section{PUBLISHER STATEMENT}

This work is made available according to the conditions of the Creative Commons Attribution-NonCommercialNoDerivatives 4.0 International (CC BY-NC-ND 4.0) licence. Full details of this licence are available at: https://creativecommons.org/licenses/by-nc-nd/4.0/

\section{LICENCE}

CC BY-NC-ND 4.0

\section{REPOSITORY RECORD}

Cruz-Manzo, Samuel, Rui Chen, and Paul S. Greenwood. 2015. "An Impedance Model for Analysis of EIS of Polymer Electrolyte Fuel Cells Under Hydrogen Peroxide Formation in the Cathode”. figshare. https://hdl.handle.net/2134/17535. 


\title{
An Impedance Model for Analysis of EIS of Polymer Electrolyte Fuel Cells under Hydrogen Peroxide Formation in the Cathode
}

\author{
Samuel Cruz-Manzo*, Rui Chen and Paul Greenwood \\ Department of Aeronautical and Automotive Engineering, Loughborough University, Leicestershire \\ LE11 3TU, United Kingdom \\ *E-mail: s.cruz-manzo@hotmail.com
}

\begin{abstract}
In this study, an impedance model based on electrochemical theory considering hydrogen peroxide formation during a two-step oxygen reduction reaction (ORR) in polymer electrolyte fuel cells (PEFCs) has been developed. To validate the theoretical treatment, electrochemical impedance spectroscopy (EIS) measurements were carried out in an open-cathode $16 \mathrm{~cm}^{2} \mathrm{H}_{2} /$ air PEFC stack. The results show that inductive loops at low frequencies of the impedance spectra are attributed to mechanisms related to hydrogen peroxide formation during ORR. The results also demonstrate that the mechanisms during consumption of hydrogen peroxide to form water (second-step in ORR) can be the dominating process for losses in the PEFC compared to the mechanisms during oxygen consumption to form hydrogen peroxide (first-step in ORR). Oxygen transport limitations can be a result of hydrogen peroxide adsorbed onto the surface of the electrode which reduces the number of active sites in the cathode catalyst layer for oxygen to react. This study could support results from other experimental techniques to identify hydrogen peroxide formation during the ORR that limit the performance of PEFCs.
\end{abstract}

Key words: EIS, hydrogen peroxide, PEFC, two-step oxygen reaction, impedance model

\section{Introduction}

Electrochemical impedance spectroscopy (EIS) is a powerful experimental technique that can be applied in-situ for diagnosis of polymer electrolyte fuel cell (PEFC) performance. The impedance response resulting from EIS represents the electrochemical mechanisms of the PEFC in the frequency domain. It can be shown in a Nyquist plot showing real and imaginary components, the magnitude and phase of the impedance as a function of frequency can also be plotted in a Bode plot. The use of electrical equivalent circuits with the experimental EIS technique is a well-established methodology to characterise processes in the PEFC. An electrical equivalent circuit can represent an identical impedance response to that obtained from the PEFC studied. Each electrical 
component in the electrical equivalent circuit can describe a physical process that takes place in the PEFC. In the authors' previous study [1], an electrical equivalent circuit based on electrochemical theory was developed to simulate and characterise the frequency response of the PEFC at any current of the polarisation curve. However, the electrical circuit had limitations in reproducing EIS measurements with positive imaginary components at low frequencies. EIS measurements with positive imaginary components at low frequencies are known as an inductive loop and have been reported in EIS measurements of PEFCs [2,3]. Makharia et al. [3] suggested that the possible reasons for this inductive effect at low frequencies are the side reaction and intermediates involved in fuel cell reactions. Roy et al. [4] developed impedance models to account for the reaction mechanisms that may be responsible for the inductive response at low frequencies; the models propose the formation of hydrogen peroxide and platinum dissolution during the oxygen reduction reaction (ORR). It has been reported [5] that crossover of hydrogen to the cathode facilitates the reaction of oxygen and hydrogen at the cathode, generating hydroxyl and hydroperoxyl radicals which react further to produce hydrogen peroxide at the cathode. The hypothesis that hydrogen peroxide may be formed at the cathode of a fuel cell is supported by the results of Inaba et al. [6]. In this study an impedance model considering fundamental electrode theory and considering hydrogen peroxide formation in a two-step ORR has been developed. Modelling considerations based on EIS theory were taken into account to simplify the mathematical treatment, the high frequency region related to ionic diffusion mechanisms in porous electrodes found in the previous study [1] were not considered here. The focus of the current study is at the low frequency range where the mechanisms relating to hydrogen peroxide formation during the oxygen reduction are represented. The impedance model considering formation of hydrogen peroxide during a two-step ORR was validated against EIS measurements carried out in an opencathode $16 \mathrm{~cm}^{2}$ PEFC stack.

\section{Electrochemical mechanisms of hydrogen peroxide formation during ORR}

The two-step ORR which yields the formation of hydrogen peroxide $\left(\mathrm{H}_{2} \mathrm{O}_{2}\right)$ and the formation of water $\left(\mathrm{H}_{2} \mathrm{O}\right)$ has been reported in the literature $[4,7]$ as:

$$
\begin{aligned}
& \mathrm{O}_{2}+2 \mathrm{H}^{+}+2 e^{-} \stackrel{k 1}{\rightarrow} \mathrm{H}_{2} \mathrm{O}_{2} \\
& \mathrm{H}_{2} \mathrm{O}_{2}+2 \mathrm{H}^{+}+2 e^{-} \stackrel{k 2}{\rightarrow} 2 \mathrm{H}_{2} \mathrm{O}
\end{aligned}
$$

The current densities corresponding to reactions (1) and (2) have been reported in the literature [8] as:

$i_{O_{2}}=-n F k_{1} C_{O_{2}} c_{H^{+}}^{3 / 2}\left(1-\gamma_{H_{2} O_{2}}\right) \exp \left(-b_{O_{2}} V\right)$ 
$i_{\mathrm{H}_{2} \mathrm{O}_{2}}=-n F k_{2} C_{\mathrm{H}_{2} \mathrm{O}_{2}} c_{\mathrm{H}^{+}}^{3 / 2} \gamma_{\mathrm{H}_{2} \mathrm{O}_{2}} \exp \left(-b_{\mathrm{H}_{2} \mathrm{O}_{2}} V\right)$

where $F$ is the Faraday constant, $k_{i}$ is the rate constant which depends on the global order of reaction, $c_{i}$ is the concentration at the electrode surface, $n$ is the number of electrons consumed during the reaction, $\gamma_{\mathrm{H}_{2} \mathrm{O}_{2}}$ is the fractional surface coverage of hydrogen peroxide, $b_{i}$ is the apparent Tafel slope, and $V$ is the electrode potential. The following assumptions are considered to facilitate the mathematical treatment:

1. This study ignores hydrogen peroxide diffusion in the CCL during EIS measurements as a first approximation. Inaba et al. [6] reported that when Pt/C catalysts are highly agglomerated, the $\mathrm{H}_{2} \mathrm{O}_{2}$ molecules easily diffuse to nearby $\mathrm{Pt} / \mathrm{C}$ particles where they are transformed to water. To account for hydrogen peroxide diffusion during EIS measurements, the effect of particle size, interactions between Pt particles and the substrate carbon on Pt/C agglomeration should be studied and considered in the modelling work. This will be addressed in future work.

2. Sethuraman et al. [9] reported that the rate of hydrogen peroxide formation during the ORR is increased with increasing proton concentration. Proton concentration in the CCL is a function of the amount of ionomer or electrolyte in the macropore spaces between agglomerates [10]. In this study, it has been considered that there is no effect to the opposition of flow of protons in the CCL on hydrogen peroxide formation. Proton resistance in the CCL is neglected. This simplified the mathematical treatment by considering that the concentration of protons across the CCL is constant from the CCLPEM interface to the Pt/C catalyst agglomerates.

3. There are three modes of transport of oxygen in the CCL which can have an effect on mass transport limitations: gas-diffusion in the electrode-pore, dissolved oxygen diffusion in the liquid water surrounding the agglomerate, and dissolved oxygen in the ionomer phase [11]. The finite diffusion distance for oxygen to reach the reaction sites in the CCL forms a complicated network of multi-phase parallel and serial paths. EIS only measures bulk parameters in the total CCL thickness and reflects a total mass transport resistance and a total finite diffusion distance for the three modes of oxygen transport in the CCL, therefore diffusion of oxygen in the CCL will be considered from the gas diffusion layer (GDL)-CCL interface to the CCL-PEM interface. This will simplify the mathematical analysis, and therefore the resulting model will present parameters commonly known in the 
electrochemical area such as the Warburg impedance [11,12] which allows the characterisation of oxygen transport limitations during EIS measurements.

Taking into account the first and second assumptions previously defined, Eqs. 3 and 4 can be defined as:

$$
\begin{aligned}
& i_{\mathrm{O}_{2}}=-n F k_{1} C_{\mathrm{O}_{2}} c_{e q, \mathrm{H}^{+}}^{3 / 2}\left(1-\gamma_{\mathrm{H}_{2} \mathrm{O}_{2}}\right) \exp \left(-b_{\mathrm{O}_{2}} V\right) \\
& i_{\mathrm{H}_{2} \mathrm{O}_{2}}=-n F k_{2} C_{e q, \mathrm{H}_{2} \mathrm{O}_{2}} c_{e q, \mathrm{H}^{+}}^{3 / 2} \gamma_{\mathrm{H}_{2} \mathrm{O}_{2}} \exp \left(-b_{\mathrm{H}_{2} \mathrm{O}_{2}} V\right)
\end{aligned}
$$

where $c_{e q, i}$ represents the concentration at equilibrium conditions as it is assumed that surface concentration of protons and hydrogen peroxide is constant.

The rate at which the transfer of charge occurs at equilibrium conditions is known as the exchange current. The exchange current densities in a two-step electron transfer reaction are described in Appendix A. The exchange current densities for reactions (1) and (2) at equilibrium conditions with $V=V_{e q, i}$ can be defined as:

$$
\begin{aligned}
& i_{0, \mathrm{O}_{2}}=n F k_{1} C_{e q, \mathrm{O}_{2}} c_{e q, \mathrm{H}^{+}}^{3 / 2}\left(1-\gamma_{e q, \mathrm{H}_{2} \mathrm{O}_{2}}\right) \exp \left(-b_{\mathrm{O}_{2}} V_{e q, \mathrm{O}_{2}}\right) \\
& i_{0, \mathrm{H}_{2} \mathrm{O}_{2}}=n F k_{2} C_{e q, \mathrm{H}_{2} \mathrm{O}_{2}} c_{e q, \mathrm{H}^{+}}^{3 / 2} \gamma_{e q, \mathrm{H}_{2} \mathrm{O}_{2}} \exp \left(-b_{\mathrm{H}_{2} \mathrm{O}_{2}} V_{e q, \mathrm{H}_{2} \mathrm{O}_{2}}\right)
\end{aligned}
$$

where $i_{0, i}$ represents the exchange current density, $\gamma_{e q, \mathrm{H}_{2} \mathrm{O}_{2}}$ is the fractional surface coverage of hydrogen peroxide under equilibrium conditions and $V_{e q, i}$ is the equilibrium potential.

Multiplying both terms of Eq. 5 by $c_{e q, O_{2}}\left(1-\gamma_{e q, H_{2} O_{2}}\right) \exp \left(-b_{\mathrm{O}_{2}} V_{e q, \mathrm{O}_{2}}\right) \quad$ and similarly Eq. 6 by $\gamma_{e q, \mathrm{H}_{2} \mathrm{O}_{2}} \exp \left(-b_{\mathrm{H}_{2} \mathrm{O}_{2}} V_{e q, \mathrm{H}_{2} \mathrm{O}_{2}}\right)$, and substituting Eqs. 7 and 8 yields:

$$
\begin{aligned}
& i_{\mathrm{O}_{2}}=-i_{0, \mathrm{O}_{2}} \frac{c_{\mathrm{O}_{2}}}{C_{e q, \mathrm{O}_{2}}} \frac{\left(1-\gamma_{\mathrm{H}_{2} \mathrm{O}_{2}}\right)}{\left(1-\gamma_{e q, \mathrm{H}_{2} \mathrm{O}_{2}}\right)} \exp \left[-b_{\mathrm{O}_{2}}\left(V-V_{e q, \mathrm{O}_{2}}\right)\right] \\
& i_{\mathrm{H}_{2} \mathrm{O}_{2}}=-i_{0, \mathrm{H}_{2} \mathrm{O}_{2}} \frac{\gamma_{\mathrm{H}_{2} \mathrm{O}_{2}}}{\gamma_{e q, \mathrm{H}_{2} \mathrm{O}_{2}}} \exp \left[-b_{\mathrm{H}_{2} \mathrm{O}_{2}}\left(V-V_{e q, \mathrm{H}_{2} \mathrm{O}_{2}}\right)\right]
\end{aligned}
$$

Assuming that the formation of hydrogen peroxide is governed by the Langmuir isothermal, it is possible to define the total current and the variation rate of $\gamma_{\mathrm{H}_{2} \mathrm{O}_{2}}$ as [13]:

$$
i=i_{\mathrm{O}_{2}}+i_{\mathrm{H}_{2} \mathrm{O}_{2}}
$$


$F \beta \frac{d \gamma_{\mathrm{H}_{2} \mathrm{O}_{2}}}{d t}=i_{\mathrm{O}_{2}}-i_{\mathrm{H}_{2} \mathrm{O}_{2}}$

where $\beta$ is the maximum surface coverage by hydrogen peroxide.

Substituting Eqs. 9 and 10 into Eqs. 11 and 12, yields:

$$
\begin{aligned}
& i=-i_{0, \mathrm{O}_{2}} \frac{c_{\mathrm{O}_{2}}}{e_{e q, \mathrm{O}_{2}}} \frac{\left(1-\gamma_{\mathrm{H}_{2} \mathrm{O}_{2}}\right)}{\left(1-\gamma_{e q, \mathrm{H}_{2} \mathrm{O}_{2}}\right)} \exp \left[-b_{\mathrm{O}_{2}}\left(V-V_{e q, \mathrm{O}_{2}}\right)\right]-i_{0, \mathrm{H}_{2} \mathrm{O}_{2}} \frac{\gamma_{\mathrm{H}_{2} \mathrm{O}_{2}}}{\gamma_{e q, \mathrm{H}_{2} \mathrm{O}_{2}}} \exp \left[-b_{\mathrm{H}_{2} \mathrm{O}_{2}}\left(V-V_{e q, \mathrm{H}_{2} \mathrm{O}_{2}}\right)\right] \\
& \left.F \beta \frac{d \gamma_{\mathrm{H}_{2} \mathrm{O}_{2}}}{d t}=-i_{0, \mathrm{O}_{2}} \frac{c_{\mathrm{O}_{2}}}{c_{e q, \mathrm{O}_{2}}} \frac{\left(1-\gamma_{\mathrm{H}_{2} \mathrm{O}_{2}}\right)}{\left(1-\gamma_{e q, \mathrm{H}_{2} \mathrm{O}_{2}}\right.}\right) \exp \left[-b_{\mathrm{O}_{2}}\left(V-V_{e q, \mathrm{O}_{2}}\right)\right]+i_{0, \mathrm{H}_{2} \mathrm{O}_{2}} \frac{\gamma_{\mathrm{H}_{2} \mathrm{O}_{2}}}{\gamma_{e q, \mathrm{H}_{2} \mathrm{O}_{2}}} \exp \left[-b_{\mathrm{H}_{2} \mathrm{O}_{2}}\left(V-V_{e q, \mathrm{H}_{2} \mathrm{O}_{2}}\right)\right]
\end{aligned}
$$

\section{1 ac impedance response}

If a small ac perturbation is applied to the working electrode, the EIS technique allows the use of a linear equation to simulate impedance spectra. A linear model can be derived using the Taylor series expansion as expressed below:

$\tilde{i}=\left(\frac{\partial i}{\partial V}\right)_{s s} \tilde{V}+\left(\frac{\partial i}{\partial \gamma_{H_{2} \mathrm{O}_{2}}}\right)_{\mathrm{ss}} \tilde{\gamma}_{\mathrm{H}_{2} \mathrm{O}_{2}}$

To facilitate the mathematical treatment, the small disturbance of oxygen $\tilde{\mathrm{O}_{2}} \sim$ from the ac perturbation is not considered in Eq. 15. Based on experimental EIS measurements in which physical parameters are measured across the entire CCL, the change in oxygen concentration during the ORR will be considered from the PEMCCL interface $c_{\mathrm{O}_{2}}^{\prime}$ to the CCL-GDL interface ${ }_{{ }_{e q, O_{2}}}$. The term that defines the change of oxygen concentration from the GDL-CCL interface to the PEM-CCL interface at the frequency domain has already been developed in the authors' previous study [1] and will be considered in the next section. It will be possible to incorporate the Warburg Impedance, which has been broadly used in the analysis of oxygen transport limitations in experimental EIS measurements of PEFCs, into the mathematical treatment.

The complex value of $\tilde{\gamma}_{\mathrm{H}_{2} \mathrm{O}_{2}}$ can be related to $\tilde{V}$ if Eq. 12 is linearized by the following equation [14]:

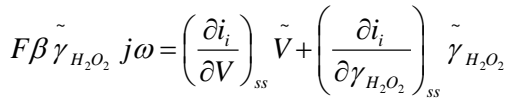

where $\omega$ is the angular frequency and $j$ is the imaginary component. 
Applying Eqs. 13 and 14 into Eqs. 15 and 16 and considering the oxygen concentration at the PEM-CCL interface $c_{\mathrm{O}_{2}}=c_{\mathrm{O}_{2}}^{\prime}$ yields:

$$
\begin{aligned}
& \tilde{i}=\left[\frac{i_{0, O_{2}} b_{O_{2}} c_{O_{2}}^{\prime}\left(1-\gamma_{\mathrm{H}_{2} \mathrm{O}_{2}, \mathrm{ss}}\right)}{c_{e q, \mathrm{O}_{2}}\left(1-\gamma_{e q, \mathrm{H}_{2}, \mathrm{Ss}}\right)} \exp \left(-b_{\mathrm{O}_{2}} \eta_{\mathrm{O}_{2}, \mathrm{ss}}\right)+\frac{i_{0, \mathrm{H}_{2} \mathrm{O}_{2}} b_{\mathrm{H}_{2} \mathrm{O}_{2}} \gamma_{\mathrm{H}_{2} \mathrm{O}_{2}, \mathrm{ss}}}{\gamma_{e q, \mathrm{H}_{2}, \mathrm{O}_{2}, \mathrm{ss}}} \exp \left(-b_{\mathrm{H}_{2} \mathrm{O}_{2}} \eta_{\mathrm{H}_{2} \mathrm{O}_{2}, \mathrm{ss}}\right)\right] \tilde{V}+\left[\frac{i_{0, \mathrm{O}_{2}} c_{\mathrm{O}_{2}}^{\prime}}{c_{e q, \mathrm{O}_{2}}\left(1-\gamma_{e q, \mathrm{H}_{2} \mathrm{O}_{2}, \mathrm{ss}}\right)} \exp \left(-b_{\mathrm{O}_{2}} \eta_{\mathrm{O}_{2}, \mathrm{ss}}\right)-\frac{i_{0, \mathrm{H}_{2} \mathrm{O}_{2}}}{\gamma_{e q, \mathrm{H}_{2} \mathrm{O}_{2}, \mathrm{ss}}} \exp \left(-b_{\mathrm{H}_{2} \mathrm{O}_{2}} \eta_{\mathrm{H}_{2} \mathrm{O}_{2}, \mathrm{ss}}\right)\right] \tilde{\gamma}_{\mathrm{H}_{2} \mathrm{O}_{2}} \\
& \left.F \beta \tilde{\gamma}_{\mathrm{H}_{2} \mathrm{O}_{2}} j \omega=\left[\frac{i_{0, \mathrm{O}_{2}} b_{\mathrm{O}_{2}} c_{\mathrm{O}_{2}}^{\prime}\left(1-\gamma_{\mathrm{H}_{2} \mathrm{O}_{2}, \mathrm{ss}}\right)}{c_{e q, \mathrm{O}_{2}}\left(1-\gamma_{e q, \mathrm{H}_{2} \mathrm{O}_{2}, \mathrm{ss}}\right)} \exp \left(-b_{\mathrm{O}_{2}} \eta_{\mathrm{O}_{2}, \mathrm{ss}}\right)-\frac{i_{0, \mathrm{H}_{2} \mathrm{O}_{2}} b_{\mathrm{H}_{2} \mathrm{O}_{2}} \gamma_{\mathrm{H}_{2} \mathrm{O}_{2}, \mathrm{ss}}}{\gamma_{e q, \mathrm{H}_{2} \mathrm{O}_{2}, \mathrm{ss}}} \exp \left(-b_{\mathrm{H}_{2} \mathrm{O}_{2}} \eta_{\mathrm{H}_{2} \mathrm{O}_{2}, \mathrm{ss}}\right)\right] \tilde{V}+\left[\frac{i_{0, \mathrm{O}_{2}} c_{\mathrm{O}_{2}}^{\prime}}{c_{e q, \mathrm{O}_{2}}\left(1-\gamma_{e q, \mathrm{H}_{2} \mathrm{O}_{2}, \mathrm{ss}}\right.}\right) \exp \left(-b_{\mathrm{O}_{2}} \eta_{\mathrm{O}_{2}, \mathrm{ss}}\right)+\frac{i_{0, \mathrm{H}_{2} \mathrm{O}_{2}}}{\gamma_{e q, \mathrm{H}_{2} \mathrm{O}_{2}, \mathrm{ss}}} \exp \left(-b_{\mathrm{H}_{2} \mathrm{O}_{2}} \eta_{\mathrm{H}_{2} \mathrm{O}_{2}, \mathrm{ss}}\right)\right] \tilde{\gamma}_{\mathrm{H}_{2} \mathrm{O}_{2}}
\end{aligned}
$$

where the subscript ss represents the steady-state, $\eta_{i, s s}=V_{s s}-V_{e q, i, s s}$ is the overpotential at steady-state, $c_{O_{2}}^{\prime}$ is the

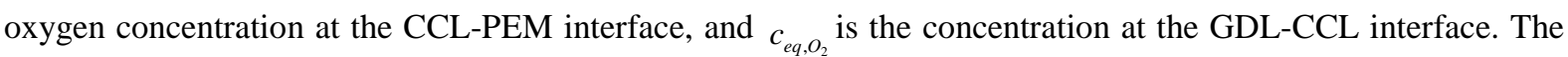
electrode surface coverage of hydrogen peroxide at steady-state $\gamma_{\mathrm{H}_{2} \mathrm{O}_{2}, \text { ss }}$ can be calculated from Eq. 14 considering $d \gamma_{\mathrm{H}_{2} \mathrm{O}_{2}} / d t=0$ and $c_{\mathrm{O}_{2}}=c_{\mathrm{O}_{2}}^{\prime}$

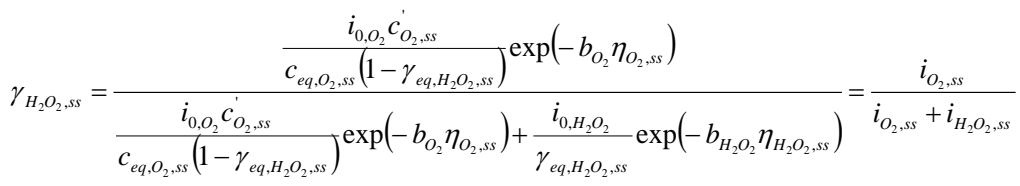

The electrode surface coverage of hydrogen peroxide at steady-state represented in Eq. 19 can be expressed in terms of steady-state currents $i_{i, s s}$; this can be demonstrated in Appendix B. Epelboin and Keddam [15] defined the coverage coefficient of adsorbed intermediate species at steady-state in a two-step reaction as the ratio between the partial current of the first reaction and the sum of the current of the first and second reactions.

The change in oxygen concentration across the CCL resulting from the small ac disturbance of the surface coverage of hydrogen peroxide formation in the frequency domain $\tilde{\gamma}_{\mathrm{H}_{2} \mathrm{O}_{2}}$ is considered negligible. Therefore, the ratio of oxygen concentration between the CCL-PEM and GDL-CCL interfaces $c_{\mathrm{O}_{2}}^{\prime} / c_{e q, \mathrm{O}_{2}}$, which are multiplied by $\tilde{\gamma}_{\mathrm{H}_{2} \mathrm{O}}$ in Eqs. 17 and 18 (third term on the right hand side), is considered to be steady-state. Under such considerations, it is possible to define Eqs. 17 and 18 in terms of charge transfer resistances and steady-state currents:

$\tilde{i}=\left[\frac{c_{\mathrm{O}_{2}}^{\prime}}{c_{e q, \mathrm{O}_{2}}} \frac{1}{R_{\mathrm{O}_{2}}}+\frac{1}{R_{\mathrm{H}_{2} \mathrm{O}_{2}}}\right] \tilde{V}+\left[i_{\mathrm{H}_{2} \mathrm{O}_{2}, \mathrm{ss}}-i_{\mathrm{O}_{2}, \mathrm{ss}}\right] \tilde{\gamma}_{\mathrm{H}_{2} \mathrm{O}_{2}}$ 
$F \beta \tilde{\gamma}_{\mathrm{H}_{2} \mathrm{O}_{2}} j \omega=\left[\frac{c_{\mathrm{O}_{2}}^{\prime}}{c_{e q, \mathrm{O}_{2}}} \frac{1}{R_{\mathrm{O}_{2}}}-\frac{1}{R_{\mathrm{H}_{2} \mathrm{O}_{2}}}\right] \tilde{V}-\left[i_{\mathrm{O}_{2}, \mathrm{ss}}+i_{\mathrm{H}_{2} \mathrm{O}_{2}, \mathrm{ss}}\right] \tilde{\gamma}_{\mathrm{H}_{2} \mathrm{O}_{2}}$

where $R_{i}$ represents the charge transfer resistance:

$$
R_{\mathrm{O}_{2}}=\frac{1-\gamma_{\mathrm{eq}_{\mathrm{H}} \mathrm{H}_{2} \mathrm{O}_{2}, \mathrm{ss}}}{i_{0, \mathrm{O}_{2}} b_{\mathrm{O}_{2}} \exp \left(-b_{\mathrm{O}_{2}} \eta_{O_{2}, \mathrm{ss}}\right)\left(1-\gamma_{\mathrm{H}_{2} \mathrm{O}_{2}, \mathrm{ss}}\right)} \quad R_{\mathrm{H}_{2} \mathrm{O}_{2}}=\frac{\gamma_{\mathrm{eq}_{\mathrm{H}} \mathrm{H}_{2}, \mathrm{ss}}}{i_{0_{0, \mathrm{H}_{2} \mathrm{O}_{2}} b_{\mathrm{H}_{2} \mathrm{O}_{2}}} \exp \left(-b_{\mathrm{H}_{2} \mathrm{O}_{2}} \eta_{\mathrm{H}_{2} \mathrm{O}_{2}, \mathrm{ss}}\right) \gamma_{\mathrm{H}_{2} \mathrm{O}_{2}, \mathrm{ss}}}
$$

and $i_{i, s s}$ represents the steady-state current:

$i_{\mathrm{O}_{2}, \mathrm{ss}}=-\frac{i_{0, \mathrm{O}_{2}} c_{O_{2}, \mathrm{ss}}^{\prime}}{c_{e q, O_{2}, \mathrm{ss}}\left(1-\gamma_{\text {eq, } \mathrm{H}_{2} \mathrm{O}_{2}, \mathrm{ss}}\right.} \exp \left(-b_{\mathrm{O}_{2}} \eta_{\mathrm{O}_{2}, \mathrm{ss}}\right) \quad i_{\mathrm{H}_{2} \mathrm{O}_{2}, \mathrm{ss}}=-\frac{i_{0, \mathrm{H}_{2} \mathrm{O}_{2}}}{\gamma_{e q, \mathrm{H}_{2} \mathrm{O}_{2}, \mathrm{ss}}} \exp \left(-b_{\mathrm{H}_{2} \mathrm{O}_{2}} \eta_{\mathrm{H}_{2} \mathrm{O}_{2}, \mathrm{ss}}\right)$

\subsection{Oxygen transport limitations}

The oxygen concentration at the electrode surface depends on the diffusion of oxygen through the multiphase via parallel and serial paths in the CCL [16]. In the authors' previous study [1] the ratio between oxygen concentrations at the CCL-PEM and CCL-GDL interfaces in the frequency domain was derived to characterise oxygen transport limitations in the impedance response of PEFCs. This ratio between oxygen concentrations is considered, as the EIS technique measures the change in oxygen concentration in the total CCL. This also allows the derivation of the Warburg Impedance which has been broadly used in the EIS area [11,12] to characterise oxygen transport limitations in the frequency domain during PEFC operation. The ratio of oxygen concentration at the PEM-CCL and GDL-CCL interface at the frequency domain is expressed as [1]:

$$
\frac{c_{\mathrm{O}_{2}}^{\prime}}{c_{e q, O_{2}}}=\frac{R_{\mathrm{O}_{2}}}{R_{\mathrm{O}_{2}}+Z_{W}}
$$

where $R_{\mathrm{O}_{2}}$ is the charge transfer resistance for the oxygen reduction which can be represented through Eq. 22 and

$$
Z_{W}=R_{W} \frac{\tanh \left(j \omega T_{W}\right)^{0.5}}{\left(j \omega T_{W}\right)^{0.5}}
$$

is known as the Warburg Impedance [11,12] and characterises oxygen transport limitations in EIS measurements of PEFCs, with

$$
R_{W}=\frac{R T \delta}{z^{2} F^{2} C_{O}^{*} D}
$$


defined as the resistance of the diffusion process and

$T_{W}=\frac{\delta^{2}}{D}$

defined as the time constant to diffuse oxygen through the CCL.

\section{Electrochemical Impedance of the PEFC under Hydrogen Peroxide Formation}

Substituting Eq. 26 into Eqs. 20 and 21 gives:

$$
\begin{aligned}
& \tilde{i}=\left[\frac{1}{R_{\mathrm{O}_{2}}+Z_{\mathrm{W}}}+\frac{1}{R_{\mathrm{H}_{2} \mathrm{O}_{2}}}\right] \tilde{V}+\left[i_{\mathrm{H}_{2} \mathrm{O}_{2}, \mathrm{ss}}-i_{\mathrm{O}_{2}, \mathrm{ss}}\right] \tilde{\gamma}_{\mathrm{H}_{2} \mathrm{O}_{2}} \\
& F \beta \tilde{\gamma}_{\mathrm{H}_{2} \mathrm{O}_{2}} j \omega=\left[\frac{1}{R_{\mathrm{O}_{2}}+Z_{W}}-\frac{1}{R_{\mathrm{H}_{2} \mathrm{O}_{2}}}\right] \tilde{V}-\left[i_{\mathrm{O}_{2}, \mathrm{ss}}+i_{\mathrm{H}_{2} \mathrm{O}_{2}, \mathrm{ss}}\right] \tilde{\gamma}_{\mathrm{H}_{2} \mathrm{O}_{2}}
\end{aligned}
$$

Arranging Eq. 31 for $\tilde{\gamma}_{\mathrm{H}_{2} \mathrm{O}_{2}}$ yields:

$$
\tilde{\gamma}_{\mathrm{H}_{2} \mathrm{O}_{2}}=\left[\frac{R_{\mathrm{H}_{2} \mathrm{O}_{2}}-R_{\mathrm{O}_{2}}-Z_{W}}{R_{\mathrm{H}_{2} \mathrm{O}_{2}}\left(R_{\mathrm{O}_{2}}+Z_{W}\right)\left(F \beta j \omega+i_{O_{2}, \mathrm{ss}}+i_{\mathrm{H}_{2} \mathrm{O}_{2}, \mathrm{ss}}\right)}\right] \tilde{V}
$$

Substituting Eq. 32 into Eq. 30 yields:

$$
\tilde{i}=\left[\frac{1}{R_{\mathrm{O}_{2}}+Z_{\mathrm{W}}}+\frac{1}{R_{\mathrm{H}_{2} \mathrm{O}_{2}}}+\frac{\left(i_{\mathrm{H}_{2} \mathrm{O}_{2}, \mathrm{ss}}-i_{\mathrm{O}_{2}, \mathrm{ss}}\right)\left(R_{\mathrm{H}_{2} \mathrm{O}_{2}}-R_{\mathrm{O}_{2}}-Z_{\mathrm{W}}\right)}{R_{\mathrm{H}_{2} \mathrm{O}_{2}}\left(R_{\mathrm{O}_{2}}+Z_{\mathrm{W}}\right)\left(F \beta j \omega+i_{\mathrm{O}_{2}, \mathrm{ss}}+i_{\mathrm{H}_{2} \mathrm{O}_{2}, \mathrm{ss}}\right)}\right] \tilde{V}
$$

The CCL is formed by a double layer structure of the interface between dissimilar materials, i.e., the electrodeelectrolyte interface. The electrode represents the electron-conducting network of carbon-supported platinum agglomerates while the electrolyte represents the ion-conducting dispersion of Nafion. At this interface an electric field is present and has a determinant role in the charge distribution within the reactants as well as in the position and orientation of the reactant to form the desired products. This double layer can behave like a capacitor that is in parallel with the electrode reactions; the current passing from the electrode to the electrolyte can either take part in the charge transfer reactions or contribute to the charge in the capacitive effect. The electrochemical reaction in the electrode results in an inhomogeneous distribution of charge in the catalyst layer. As a result, a non-ideal capacitor (Constant Phase Element) [17] defined in the frequency domain $j \omega$ has to be considered in the theoretical treatment, in order to correct for this inhomogeneity: 
$\tilde{i}=\left[\frac{1}{R_{\mathrm{O}_{2}}+Z_{\mathrm{W}}}+\frac{1}{R_{\mathrm{H}_{2} \mathrm{O}_{2}}}+\frac{\left(i_{\mathrm{H}_{2} \mathrm{O}_{2}, \mathrm{ss}}-i_{\mathrm{O}_{2}, \mathrm{~s}}\right)\left(R_{\mathrm{H}_{2} \mathrm{O}_{2}}-R_{\mathrm{O}_{2}}-Z_{\mathrm{W}}\right)}{R_{\mathrm{H}_{2} \mathrm{O}_{2}}\left(R_{\mathrm{O}_{2}}+Z_{\mathrm{W}}\right)\left(F \beta j \omega+i_{O_{2}, \mathrm{sS}}+i_{\mathrm{H}_{2} O_{2}, \mathrm{ss}}\right)}\right] \tilde{V}+Y(j \omega)^{\mathrm{p}} \tilde{V}$

where $Y$ represents a parameter related to capacitance and superscript $P$ represents a parameter to correct the inhomogeneity in the distribution of charge.

Eq. 34 can be rearranged to express the electrical current that enters a circuit composed of resistive, and capacitive elements, as shown in Fig. 1

giving:

$\tilde{i}=\left[\frac{1}{R_{\mathrm{O}_{2}}+Z_{W}}+\frac{1}{R_{H_{2} \mathrm{O}_{2}}}+A \phi+Y(j \omega)^{p}\right] \tilde{V}$

where

$A \phi=\frac{1}{(j \omega+1) R \phi}, \quad \tau=\frac{F \beta}{i_{O_{2}, \mathrm{ss}}+i_{\mathrm{H}_{2} \mathrm{O}_{2}, \mathrm{ss}}}, \quad R \phi=\frac{R_{\mathrm{H}_{2} \mathrm{O}_{2}}\left(R_{\mathrm{O}_{2}}+Z_{W}\right) I_{\mathrm{s}}}{\left(R_{\mathrm{H}_{2} \mathrm{O}_{2}}-R_{\mathrm{O}_{2}}-Z_{\mathrm{W}}\right)}$, and $I_{\mathrm{s}}=\frac{\left(i_{O_{2}, \mathrm{~s}}+i_{\mathrm{H}_{2} \mathrm{O}_{2}, \mathrm{~s}}\right)}{\left(i_{\mathrm{H}_{2} \mathrm{O}_{2}, \mathrm{~s}}-i_{\mathrm{O}_{2}, \mathrm{ss}}\right)}$

characterise inductive loops at low frequencies in the impedance response of PEFCs.

Rearranging Eq. 35 yields the electrochemical impedance of the cathode accounting for hydrogen peroxide formation during the ORR:

$$
Z c=\left[\frac{1}{\frac{1}{R_{\mathrm{O}_{2}}+Z_{W}}+\frac{1}{R_{\mathrm{H}_{2} \mathrm{O}_{2}}}+A \phi+Y(j \omega)^{p}}\right]
$$

The hydrogen oxidation reaction (HOR) mechanisms occurring at the anode have been proposed by Malevich et al. [11] to be represented as an electrical circuit composed of a resistor (charge transfer resistance) in parallel with a capacitor (representing the double layer capacitance). HOR taking place in the anode is a faster and a less complicated reaction sequence than the ORR in the cathode and can be represented at the frequency domain as:

$$
Z a=\frac{R a}{1+j \omega R a C a}
$$

if no contaminants such as $\mathrm{CO}$ are present, where $\mathrm{Ra}$ is charge transfer resistance and $\mathrm{Ca}$ is capacitance. 
The opposition of ions flowing through the PEM, and electrons flowing through the bipolar plate and GDL can be represented by resistances connected in series. The overall process can be represented with a total resistance Rohm that accounts for the different resistances in the layers of the PEFC.

Therefore, the impedance of the PEFC including anode, cathode, and PEM can be represented through the following equation:

$Z_{P E F C}=R o h m+Z a+Z c$

where $R_{\text {ohm }}$ represents the ohmic resistance of the PEM, bipolar plates, GDL, the second term on the right hand side represents Eq. 37 and the third term represents the cathode impedance (Eq. 36). Eq. 38 can be represented through the equivalent electrical circuit shown in Fig. 2

For the specific case when the charge transfer resistance related to hydrogen peroxide reaction $R_{\mathrm{H}_{2} \mathrm{O}_{2}}$ during the second-step ORR is smaller than the sum of charge transfer resistance and mass transport resistance $R_{O_{2}}+Z_{W}$ during the first-step ORR; $R_{\phi}$ in Eq. 35 becomes negative and a capacitive loop at the low frequency end of the spectrum is predicted instead of an inductive loop, as shown in Fig. 3.

\section{Experimental}

A commercial Open-Cathode 4-cell stack with a $16 \mathrm{~cm}^{2}$ active area was used for the experimental tests. The membrane electrode assemblies (MEAs) were made of Nafion 211 with platinum loadings of $0.4 \mathrm{mg} / \mathrm{cm}^{2}$ and carbon black for the electrodes. The GDLs were made of carbon felt with $200 \mu \mathrm{m}$ width. The 4-cell stack consists of open cathodes with two 5V DC fans for oxidant supply (as air) and cooling. The stack consists of bipolar plates made of FU4369 HT material with a thickness of 5 mm. High purity hydrogen (99.999 \%) was used during the tests to reduce fuel impurities which can limit the performance of the PEFC. Open-Cathode fuel cells are commonly operated with a dead-ended hydrogen outlet; however under such a configuration a nonsteady response is expected at medium and high currents due to build-up of water. In this study the fuel cell stack was run in a through flow mode at the anode. The flow rate of hydrogen in the anode was kept constant during the experiments with a stoichiometry of 2. The hydrogen supplied was dry. The PEFC stack was operated at an ambient temperature of $22{ }^{\circ} \mathrm{C}$ and the hydrogen back pressure was held at $0.4 \mathrm{bar}(\mathrm{g})$. A polarisation curve was recorded prior to impedance measurements as shown in Fig. 4. 
EIS measurements were carried out through a Z\#106 WonATech frequency response analyser (FRA). EIS measurements were carried out at three different current densities $0.1875,0.3125$, and $0.4375 \mathrm{~A} / \mathrm{cm}^{2}$ of the polarisation curve, as shown in Fig. 4. The PEFC stack was run over 60 minutes at the required current with no variation in the voltage to ensure a steady state for EIS measurements. EIS measurements for current densities < $0.1875 \mathrm{~A} / \mathrm{cm}^{2}$ were not possible, as the low AC amplitude superimposed onto the DC current made it difficult for the FRA to distinguish between noise and response. At high current densities $>0.4365 \mathrm{~A} / \mathrm{cm}^{2}$ the fuel cell stack was not steady for a long period of time due to the high water concentration produced by the ORR. The frequency scan was performed from $10 \mathrm{kHz}$ down to $0.1 \mathrm{~Hz}$, with a 5\% AC amplitude of the DC current.

It has been commonly considered that the oxygen in the fuel cell can be electrochemically reduced directly to water without the formation of intermediate species. The hypothesis that a 2-step ORR is present during fuel cell operation is supported by the results from Inaba et al. [6]. The authors revealed that hydrogen peroxide can be formed by a two-electron reduction pathway and exists on Pt particles supported on carbon. After hydrogen peroxide is desorbed from the Pt surface, and diffuses away to the bulk of the solution. If Pt/C catalysts are highly agglomerated the $\mathrm{H}_{2} \mathrm{O}_{2}$ molecules easily diffuse to nearby $\mathrm{Pt} / \mathrm{C}$ particles where they are transformed to water by further two-electron reduction (series four-electron reduction or 2-step ORR).

\section{Experimental Validation and Results}

EIS measurements are commonly analysed by fitting an impedance model with experimental data. An increase in the number of parameters in an equation that represents the PEFC impedance response may lead to increased error in the resulting fitted values with experimental EIS. A Randles circuit as reported by Malevich et al. [11] was first fitted to the measured EIS spectra using ZView 2.9 software (Scribner Associates, Inc), as shown in Fig. 5. The Randles circuit was fitted to the EIS measurements through a complex nonlinear regression method (Levenberg-Marquardt). This allowed the estimation of $R_{\mathrm{O}_{2}}, Z_{W}, Y, P$ Rohm, and the parameters related to Za in Eq. 38. Noting that the Randles circuit shown in Fig. 5a represents the electrical circuit shown in Fig. 2 without the parameters $R_{\mathrm{H}_{2} \mathrm{O}_{2}}$ and $A \phi$ which are related to hydrogen peroxide reaction mechanisms during the ORR. 
$R \phi$ in Eq. 38 is a frequency dependent parameter, therefore it cannot be expressed as a resistor in a commercial

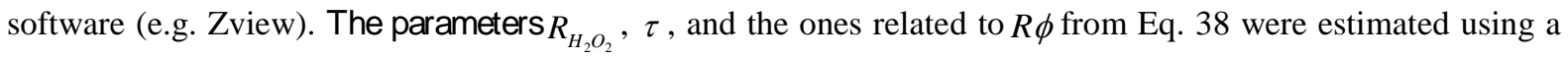
Graphic User Interface (GUI) developed in Matlab. The use of the GUI for EIS analysis has already been demonstrated in the authors' previous study $[1,18]$. The parameters $R_{\mathrm{H}_{2} \mathrm{O}_{2}}, \tau$, and from $R \phi$ were fitted to the EIS measurements using the GUI to reproduce the inductive loop at low frequencies as shown in Fig. 6. The GUI allows the fitting of the parameters from Eq. 38 to achieve a good agreement between the experimental and simulated data. The parameter $R_{\mathrm{O}_{2}}$ was recalculated to account for the charge transfer resistance of oxygen consumption during a two-step ORR. The least squares fitting method was used in order to find the best-fit between the model and the measured data. A good quality fit is obtained when the sum of the deviations squared (least square error) between the simulated and measured impedance data has a minimum value, for instance $<0.1$. The parameters of Eq. 38 extracted from the measured EIS data are shown in Table I.

Figure 6 shows that with the parameters given in Table I, the theoretical model is capable of simulating the impedance response of the PEFC stack. The results show good agreement between the measured and simulated data in the Nyquist plot. Roy et al. [4] developed an impedance model to account for formation of hydrogen peroxide during the ORR. The model was compared with experimental results, and the results show that hydrogen peroxide formation mechanisms could account for the experimentally observed low-frequency inductive loops in EIS measurements. The comparison between simulated and measured data in the current study shows a better agreement than the comparison between simulated and measured data reported by Roy et al. [4]. One of the reasons of finding a better agreement in this study is the fact that a constant phase element, which accounts for nonhomogeneous charge distribution in the catalyst layer, was considered in the modelling approach. Different to the modelling approach by Roy et al. [4] where an ideal capacitor, which represents homogenous charge distribution in the catalyst layer, was considered.

Fig. 6 shows that the diameter of the spectrum decreases from a current density of $0.1875 \mathrm{~cm}^{2}$ to $0.3125 \mathrm{~A} / \mathrm{cm}^{2}$ and increases from a current density of $0.3125 \mathrm{~A} / \mathrm{cm}^{2}$ to $0.4375 \mathrm{~A} / \mathrm{cm}^{2}$. Similar results were reported by Yuan $e t$ al. [19] when EIS measurements were carried out in a $500 \mathrm{~W}$ six-cell PEFC stack. Their results showed that the impedance spectrum decreased with increasing current up to 80 amperes, and beyond 80 amperes the impedance spectrum increased again. Paganin et al. [20] reported that when the kinetics of the ORR dominates the cell performance such as in the low current density range of the polarisation curve, the impedance spectrum mainly 
represents the charge transfer effect during the ORR and its diameter decreases with increasing current density. At high currents, the increase in diameter of the spectra with increasing current density can be attributed to an increase in oxygen transport limitations [19]. One of the disadvantages of the EIS technique is that multiple energy controlled processes during the electrochemical reaction can be masked in the impedance plot. The charge transfer resistances related to oxygen reduction $R_{\mathrm{O}_{2}}$ and hydrogen peroxide reaction $R_{\mathrm{H}_{2} \mathrm{O}_{2}}$ decrease when current density is increased from $0.1875 \mathrm{~cm}^{2}$ to $0.3125 \mathrm{~A} / \mathrm{cm}^{2}$, as shown in Tab. 1. The oxygen charge transfer resistance is smaller than the hydrogen peroxide charge transfer resistance. Tafel slopes related to a two-step ORR with hydrogen peroxide formation have been reported in the literature. The apparent Tafel slope, related to oxygen consumption to form hydrogen peroxide, has been reported to be greater than the apparent Tafel slope related to the hydrogen peroxide consumption to form water [4]. A high value of apparent Tafel slope $\left(V^{1}\right)$ decreases the value of the charge transfer resistance. Tab. 1 shows that the charge transfer resistance of hydrogen peroxide reaction increases with increasing current density from $0.3125 \mathrm{~A} / \mathrm{cm}^{2}$ to $0.4375 \mathrm{~A} / \mathrm{cm}^{2}$. This increase can be a result due to the fact that Eq. 38 does not take into account the variation of hydrogen peroxide concentration at the reaction sites. In this study, the surface concentration of hydrogen peroxide was considered constant to facilitate the mathematical treatment. The increase of hydrogen peroxide charge transfer resistance $R_{\mathrm{H}_{2} \mathrm{O}_{2}}$ can be related to a change of the value of $b_{\mathrm{H}_{2} \mathrm{O}_{2}}$ Tafel slope with increasing current density when diffusion effect is present. Further work is required to develop an analytical expression that considers diffusion of hydrogen peroxide in EIS measurements as a function of cell potential.

A further validation of the mathematical model against the modulus and phase angle of the frequency response of the measured data was carried out. Figs. 7, 8 show the comparison between measured and simulated data in Bode format. Fig. 7 shows that the model is able to reproduce the Bode modulus for all the frequencies. Fig. 8 shows a discrepancy in the phase angle between measured and simulated data at the highest frequencies ( $>5$ $\mathrm{kHz}$ ). Orazem and Tribollet [21] reported in their study that the Bode modulus and real part component of the impedance plots are relatively insensitive to the quality of the fit of a model to impedance data. The imaginary component of the impedance and Bode phase angle plots are modestly sensitive to fit quality. The ionic resistance in the CCL has been represented in EIS measurements $[3,22]$ as a $45^{\circ}$ region at high frequencies. At high frequencies (Fig. 6) it is clearly shown that the $45^{\circ}$ straight line represents the ionic resistance of the catalyst layer. The discrepancy between the measured data and simulated data in phase angle at high frequencies 
(5-10 kHz) shown in Fig. 8 can be related to the fact that the ionic resistance in the CCL was not considered in Eq. 38.

A property from EIS measurements is that as the frequency reaches a value of zero the operating conditions of the fuel cell must converge to steady state conditions [23]. This means that a resistive value (no frequency dependence) for the impedance response is expected as the frequency reaches zero. This resistive value is named polarisation resistance and is related to the slope of the E-I (polarisation) curve [24]. Roy et al. [4] reported that the presence of side reactions (e.g. hydrogen peroxide formation) has little influence on polarisation curves, as these reactions take place a low rate compared to HOR and ORR. Also the authors concluded that EIS measurements are more sensitive than polarisation curves with the side reactions present. A further study for EIS measurements in a PEFC with low rate of side reactions (no inductive loop) and inducing side reactions (inductive loop) should be carried out. This is to study the relation between polarisation resistance and the impedance response at frequencies near $0 \mathrm{~Hz}$ for both conditions.

\section{Discussion}

The electrical current during a simple electron-transfer ORR takes part in the charge transfer and simultaneously takes part in the consumption of oxygen during the ORR. This process can be represented through the Randles circuit where the faradaic impedance consists of the charge transfer resistance connected in series with the mass transport resistance (Warburg element) [11,12]. During a two-step electron transfer ORR the sum of the reactions, hydrogen peroxide formation and water formation, in the two-step ORR yields the reaction accounting for formation of water without any intermediates. The resulting electrical circuit that accounts for formation of hydrogen peroxide during the ORR can be represented through a parallel electric circuit configuration between the two-step ORR mechanisms, as shown in Fig. 1. In the study of Roy et al. [4], electrical circuits were developed to account for adsorbed species during a two-step ORR in which the impedance related to the first step of the ORR is in parallel with the impedance related to the second step of the ORR. Wagner and Gülzow [25] reported an electrical circuit configuration to account for a PEFC during poisoning of the anode with $\mathrm{CO}$ in which the anode charge transfer resistance is connected in parallel with a relaxation impedance describing the surface relaxation of the electrode-electrolyte interface. Their study reported inductive loops at low frequencies related to CO poisoning in PEFC electrodes. High purity hydrogen (99.999 \%) was used during these experimental tests, therefore the influence of CO on EIS measurements can be ruled out in this work. 
The charge transfer resistance for anode $R a$ was one order of magnitude less than the charge transfer resistances $R_{\mathrm{O}_{2}}$ and $R_{\mathrm{H}_{2} \mathrm{O}_{2}}$ related to ORR, as shown in Table 1. This demonstrates that the HOR taking place in the anode is a faster and a less complicated reaction sequence than the ORR in the cathode. Commonly it has been assumed during the analysis of EIS measurements that there is no contribution of the anode impedance to the cell impedance [12]. However, it is highly recommended to consider the anode impedance during the fitting process of EIS measurements if a reference electrode is not used within the experimental system. This would avoid uncertainly in the resulting data.

The value of charge transfer resistance $R_{\mathrm{O}_{2}}$ occurring during the first step in the ORR (oxygen consumption) was smaller than the value of the charge transfer resistance $R_{\mathrm{H}_{2} \mathrm{O}_{2}}$ during the second step in the ORR (hydrogen peroxide consumption). Hydrogen crossover from anode to cathode has been reported as the mechanism responsible for the formation of hydrogen peroxide [4]. The model predicted that when the charge transfer resistance, related to hydrogen peroxide reaction $R_{\mathrm{H}_{2} \mathrm{O}_{2}}$ during the second-step ORR, is greater than the sum of the charge transfer resistance and mass transport resistance $R_{\mathrm{O}_{2}}+Z_{W}$ during the first-step ORR an inductive loop can be seen at low frequencies of the impedance spectrum. This relation $R_{\mathrm{H}_{2} \mathrm{O}_{2}}>R_{\mathrm{O}_{2}}+Z_{W}$ was validated with experimental measurements as shown in Tab 1, and therefore demonstrates that the kinetic mechanisms during consumption of hydrogen peroxide to form water can be the dominating process for losses in the PEFC compared with the mechanisms during oxygen reduction. One of the disadvantages of the EIS technique is that the time constants related to the different electrochemical processes are overlapped in the complex-impedance plot [26]. The increase in oxygen concentration limitations during the first step of the ORR can be a result of the intermediate species adsorbed onto the electrode surface which reduce the number of active sites in the CCL for oxygen to react. From Table I it can be demonstrated that the time constant process $\tau$ which relates to the reaction of hydrogen peroxide during the second step of the ORR is greater than the time constant for oxygen to diffuse through the CCL $T_{W}$. This can be demonstrated in the EIS complex plot where the inductive loop related to hydrogen peroxide formation mechanisms are present at the lowest frequencies.

The process responsible for the inductive characteristics at low frequencies has been attributed to hydrogen crossover through the PEM [5] to form hydrogen peroxide at the cathode. Hydrogen crossover from anode to 
cathode through conventional graphite for bipolar plates due to their porous nature could also be a responsible process for hydrogen peroxide formation and inductive loops in EIS measurements.

Fig. 6 shows a slight difference in the shape of the inductive loop from experimental data compared to the simulated data. This difference could reveal that during fuel cell operation not only hydrogen peroxide formation is present but also other electrochemical mechanisms that can cause fuel cell degradation. It has been proposed [4] that platinum dissolution could also be represented as an inductive loop at low frequencies. Therefore the results shown in Fig. 6 can lead to the development of a future impedance model which combines hydrogen peroxide formation with platinum dissolution.

\section{Conclusions}

An impedance model based on hydrogen peroxide formation during the ORR has been developed to characterise EIS measurements of PEFCs featuring inductive loops at low frequencies. The current study begins by defining the electrochemical equations representing the rate of charge transfer during hydrogen peroxide formation in a two-step ORR. Modelling considerations based on EIS theory were taken into account to simplify the mathematical treatment. The equations defining the electrochemical mechanisms during the two-step ORR were transformed from the time domain to the frequency domain to simulate the frequency response of the PEFC and thus the low frequency inductive loop. The theoretical treatment is validated against the measured EIS response of an open-cathode PEFC stack. The results show that the model can predict the experimental impedance response presenting an inductive loop at low frequencies attributed to mechanisms of hydrogen peroxide reaction. The results also show that electrochemical mechanisms related to the reaction of hydrogen peroxide during the ORR can limit the PEFC performance. This study could assist with other experimental studies to identify hydrogen peroxide formation during the ORR which limit the performance of PEFCs.

\section{Acknowledgements}

The authors thank the Mexican National Council for Science and Technology (CONACYT) for the sponsorship of the Ph.D research study of S. Cruz-Manzo (Grant No. 183195).

\section{Appendix A}

Diard et al. [13] described some examples of the mechanisms represented by a two-step electron transfer reaction with an adsorbed intermediate species such as cathodic production of hydrogen: 


$$
\begin{aligned}
& H^{+}+e^{-} \leftrightarrow H_{a d s} \\
& H^{+}+H_{a d s}+e^{-} \leftrightarrow H_{2}
\end{aligned}
$$

Reactions A1 and A2 can be represented as:

$$
\begin{aligned}
& \text { reac } \tan t+e^{-} \underset{K_{r 1}}{\leftrightarrow} \text { adsorbate } \\
& (\text { reac } \tan t)+\text { adsorbate }+e^{-} \underset{K_{r 2}}{\leftrightarrow} \text { product }
\end{aligned}
$$

The net current for reactions (A3) and (A4) can be expressed as:

$$
i_{1}=F \Gamma\left\{K_{o 1} \theta-K_{r 1}(1-\theta)\right\}
$$

$i_{2}=F \Gamma\left\{K_{o 2}(1-\theta)-K_{r 2} \theta\right\}$

with $\quad K_{o j}=k_{o j} \exp \left(\alpha_{o j} F E / R T\right) \quad$ and $\quad K_{r j}=k_{r j} \exp \left(-\alpha_{r j} F E / R T\right) \quad j=1,2$

where $F$ is the Faraday constant, $\Gamma$ is the number of electrosorption sites per unit area of electrode surface, and $\theta$ is the coverage of the electrode surface by the adsorbate. The concentration of the chemical species is considered constant and is introduced into the rate constants. At equilibrium conditions $i_{1}=i_{2}=0$, the exchange current densities are defined as:

$$
\begin{aligned}
& i_{01}=F \Gamma K_{o 1}^{*} \theta_{e q}=F \Gamma K_{r 1}^{*}\left(1-\theta_{e q}\right) \\
& i_{02}=F \Gamma K_{o 2}^{*}\left(1-\theta_{e q}\right)=F \Gamma K_{r 2}^{*} \theta_{e q}
\end{aligned}
$$

with

$$
K_{o j}^{*}=k_{o j} \exp \left(\alpha_{o j} F E_{e q} / R T\right) \quad \text { and } \quad K_{r j}^{*}=k_{r j} \exp \left(-\alpha_{r j} F E_{e q} / R T\right) \quad j=1,2
$$

\section{Appendix B}

The steady-state value $\gamma_{\mathrm{H}_{2} \mathrm{O}_{2}, \mathrm{ss}}$ is calculated from Eq. 14 with $d \gamma_{\mathrm{H}_{2} \mathrm{O}_{2}} / d t=0$ and ${c_{\mathrm{O}_{2}}}=c_{\mathrm{O}_{2}}^{\prime}$ giving:

$0=-\frac{i_{0, \mathrm{O}_{2}} c_{\mathrm{O}_{2}, \mathrm{ss}}^{\prime}\left(1-\gamma_{\mathrm{H}_{2} \mathrm{O}_{2}, \mathrm{ss}}\right)}{c_{e q, \mathrm{O}_{2}, \mathrm{ss}}\left(1-\gamma_{e q, \mathrm{H}_{2} \mathrm{O}_{2}, \mathrm{ss}}\right)} \exp \left(-b_{\mathrm{O}_{2}} \eta_{\mathrm{O}_{2}, \mathrm{ss}}\right)+\frac{i_{0, \mathrm{H}_{2} \mathrm{O}_{2}} \gamma_{\mathrm{H}_{2} \mathrm{O}_{2}, \mathrm{ss}}}{\gamma_{e q, \mathrm{H}_{2} \mathrm{O}_{2}, \mathrm{ss}}} \exp \left(-b_{\mathrm{H}_{2} \mathrm{O}_{2}} \eta_{\mathrm{H}_{2} \mathrm{O}_{2}, \mathrm{ss}}\right)$

Arranging Eq. B1 for $\gamma_{\mathrm{H}_{2} \mathrm{O}_{2}, \mathrm{ss}}$ gives:

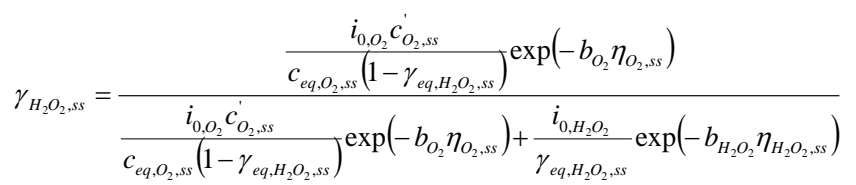

The total current for reactions (1) and (2) in steady-state, considering Eq. 13 and ${C_{\mathrm{O}_{2}}}=c_{\mathrm{O}_{2}}^{\prime}$ can be expressed as: 
$i_{s s}=-\frac{i_{0, O_{2}} c_{O_{2}, s s}^{\prime}\left(1-\gamma_{H_{2} \mathrm{O}_{2}, \mathrm{ss}}\right)}{c_{e q, \mathrm{O}_{2}, \mathrm{ss}}\left(1-\gamma_{e q, \mathrm{H}_{2} \mathrm{O}_{2}, \mathrm{ss}}\right)} \exp \left(-b_{\mathrm{O}_{2}} \eta_{\mathrm{O}_{2}, \mathrm{ss}}\right)-\frac{i_{0, \mathrm{H}_{2} \mathrm{O}_{2}} \gamma_{\mathrm{H}_{2} \mathrm{O}_{2}, \mathrm{ss}}}{\gamma_{e q, \mathrm{H}_{2} \mathrm{O}_{2}, \mathrm{ss}}} \exp \left(-b_{\mathrm{H}_{2} \mathrm{O}_{2}} \eta_{\mathrm{H}_{2} \mathrm{O}_{2}, \mathrm{ss}}\right)$

Substituting Eq. B2 into Eq. B3 yields:

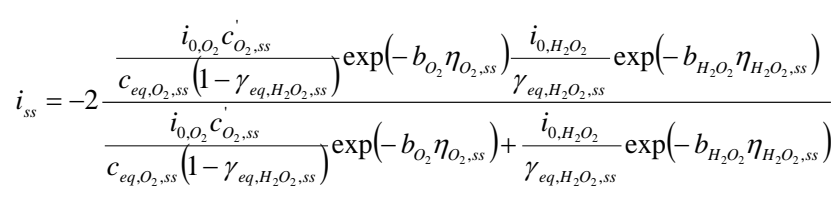

Eqs. (B2) and (B4) can be expressed in terms of steady-state currents:

$\gamma_{\mathrm{H}_{2} \mathrm{O}_{2}, \mathrm{ss}}=\frac{i_{\mathrm{O}_{2}, \mathrm{ss}}}{i_{\mathrm{O}_{2}, \mathrm{ss}}+i_{\mathrm{H}_{2} \mathrm{O}_{2}, \mathrm{ss}}}$

$i_{s s}=\frac{2 i_{O_{2}, s} i_{H_{2} O_{2}, s s}}{i_{O_{2}, s s}+i_{H_{2} O_{2}, s s}}$

with $\left.i_{O_{2}, \mathrm{ss}}=-\frac{i_{0, \mathrm{O}_{2}} c_{O_{2}, \mathrm{ss}}}{c_{e q, O_{2}, \mathrm{ss}}\left(1-\gamma_{e q, \mathrm{H}_{2} \mathrm{O}_{2}, \mathrm{ss}}\right.}\right) \exp \left(-b_{\mathrm{O}_{2}} \eta_{O_{2}, \mathrm{ss}}\right) \quad i_{\mathrm{H}_{2} \mathrm{O}_{2}, \mathrm{ss}}=-\frac{i_{0, \mathrm{H}_{2} \mathrm{O}_{2}}}{\gamma_{e q, \mathrm{H}_{2} \mathrm{O}_{2}, \mathrm{ss}}} \exp \left(-b_{\mathrm{H}_{2} \mathrm{O}_{2}} \eta_{\mathrm{H}_{2} \mathrm{O}_{2}, \mathrm{ss}}\right)$

Epelboin and Keddam [15] reported a similar relation for the total current and fractional surface coverage of hydrogen peroxide at steady-state.

\section{List of Symbols}

$b$

apparent tafel slope, $V^{-1}$

$\mathrm{Ca} \quad$ double layer capacitance in anode, $F / \mathrm{cm}^{2}$

$c_{O} \quad$ oxygen concentration at the electrode surface, $\mathrm{mol} / \mathrm{cm}^{3}$

$C_{e q, O} \quad$ oxygen concentration at equilibrium, $\mathrm{mol} / \mathrm{cm}^{3}$

$c_{O}^{\prime} \quad$ oxygen concentration at the CCL-PEM interface, $\mathrm{mol} / \mathrm{cm}^{3}$

$c_{O}^{*} \quad$ oxygen concentration at equilibrium conditions, $\mathrm{mol} / \mathrm{cm}^{3}$

D effective diffusion coefficient, $\mathrm{cm}^{2} / \mathrm{sec}$

F $\quad$ faraday constant, $96485 \mathrm{C} / \mathrm{mol}$

$j \quad$ imaginary component in impedance

i current density $\mathrm{A} / \mathrm{cm}^{2}$

$i_{0} \quad$ exchange current density, $A / \mathrm{cm}^{2}$

$i_{\text {ss }} \quad$ steady-state current density, $A / \mathrm{cm}^{2}$ 


\section{Greek}

$\beta \quad$ maximum surface coverage by hydrogen peroxide, $\mathrm{mol} / \mathrm{cm}^{2}$

$\gamma_{\mathrm{H}_{2} \mathrm{O}_{2}} \quad$ fractional surface coverage of hydrogen peroxide, dimensionless

$\gamma_{e q, H_{2} \mathrm{O}_{2}} \quad$ fractional surface coverage of hydrogen peroxide at equilibrium conditions, dimensionless

$\gamma_{\mathrm{H}_{2} \mathrm{O}_{2}, \mathrm{ss}} \quad$ surface coverage at steady-state, dimensionless

$\tilde{\gamma}_{\mathrm{H}_{2} \mathrm{O}_{2}} \quad$ deviation of variable $\gamma_{\mathrm{H}_{2} \mathrm{O}_{2}}$ in the steady-state $\gamma_{\mathrm{H}_{2} \mathrm{O}_{2}, \mathrm{ss}}$, dimensionless

$\delta$

$\eta$ deviation of variable $i$ in the steady-state $i_{s s} \cdot A / \mathrm{cm}^{2}$

rate constant of reaction

parameter related to capacitance (constant phase element)

charge transfer resistance during HOR, $\Omega . \mathrm{cm}^{2}$

charge transfer resistance, $\Omega . \mathrm{cm}^{2}$

total ohmic resistance, PEM, GDL, Plate, $\Omega . \mathrm{cm}^{2}$

resistance for the diffusion process, $\Omega . \mathrm{cm}^{2}$

laplace domain

time constant for the diffusion process, sec

time, sec

angular frequency, $\mathrm{rad} / \mathrm{sec}$

parameter related to capacitance, $(\mathrm{sec})^{P} / \Omega . \mathrm{cm}^{2}$

impedance of anode, $\Omega . \mathrm{cm}^{2}$

impedance of cathode, $\Omega . \mathrm{cm}^{2}$

impedance of PEFC, $\Omega . \mathrm{cm}^{2}$

Warburg impedance, $\Omega . \mathrm{cm}^{2}$

real part of impedance

imaginary part of impedance finite diffusion distance of oxygen transport from CCL-GDL to CCL-PEM interface, $\mathrm{cm}$ overpotential in the CCL, $V$ 


\section{References}

[1] S. Cruz-Manzo and R. Chen, J. Electroanal. Chem., 694, 45 (2013).

[2] N. V. Dale, M. D. Mann, H. Salehfar, A. M. Dhirde and T. Han, ASME J. Fuel Cell, 7 (2010) 031010/1-031010/10

[3] R. Makharia, M. F. Mathias and D. R. Baker, J. Electrochem. Soc., 152, A970 (2005).

[4] S. K. Roy, M. E. Orazem and B. Tribollet, J. Electrochem. Soc., 154, B1378 (2007).

[5] J. Xie, D. L. Wood III, K. L. More, P. Atanassov, and R. L. Borup, J. Electrochem. Soc., 152, A1011 (2005).

[6] M. Inaba, H. Yamada, J. Tokunaga, and A. Tasaka, Electrochem. Solid-State Lett., 7, A474 (2004).

[7] A. Damjanovic and V. Brusic, Electrochim. Acta, 12, 615 (1967).

[8] S. K. Roy and M. E. Orazem, ECS Trans., 3(1), 1031 (2006).

[9] Vijay A. Sethuraman, John W. Weidner, Andrew T. Haug, Sathya Motupally, and Lesia V. Protsailo, J. Electrochem. Soc., 155, (2008), B50-B57

[10] M. Eikerling, A.A. Kornyshev, J. Electroanal. Chem. 453 (1998) 89-106.

[11] D. Malevich, E. Halliop, B. A. Peppley, J. G. Pharoah, K. Karan, J. Electrochem. Soc. 156 (2009) B216-B224.

[12] N. Fouquet, C. Doulet, C. Nouillant, G. Dauphin-Tanguy, B. Ould-Bouamama, J. Power Sources 159 (2006) 920-928.

[13] J.-P. Diard, B. Le Gorrec and C. Montella, J. Electroanal. Chem., 326, 13 (1992).

[14] I. Epelboin, M. Keddam, and J. C. Lestrade, Faraday Discuss. Chem. Soc., 56, 264-275, (1973).

[15] I. Epelboin and M. Keddam, J. Electrochem. Soc., 117, 1052 (1970).

[16] Eikerling M., and Kornyshev A. A., J Electroanal. Chem., 475, (1999) pp. 107-123.

[17] C. H. Hsu and F. Mansfeld, Corrosion 57 (2001) 747-748.

[18] S. Cruz-Manzo and R. Chen, J. Electrochem. Soc., 160 (2013) F1109- F1115

[19] Yuan X., Sun J. C., Blanco S., Wang H., Zhang J., and Wilkinson D. P., J. Power Sources, 161, (2006), pp. 929-937.

[20] Paganin V. A., Oliveira C. L. F., Ticianelli E. A., Springer T. E., and Gonzalez E. R., Electrochim. Acta, 43, (1998), 761-3766.

[21] Orazem M., and Tribollet B., Electrochemical Impedance Spectroscopy, Wiley, New Jersey (2008).

[22] S. Cruz-Manzo, R. Chen and P. Rama, Journal of Fuel Cell Science and Technology, 9, (2012) 051002

[23] G. Maranzana, J. Mainka, O. Lottin, J. Dillet, A. Lamibrac, A. Thomas, and S.Didierjean, Electrochim. Acta, 83 (2012) $13-27$.

[24] N. Wagner, J. of Appl. Electrochem., 32, (2002), 859-863.

[25] N. Wagner and E. Gülzow, J. Power Sources, 127, 341 (2004).

[26] S.Cruz-Manzo, R. Chen and P. Rama, Int. J. Hydrogen Energy, 38 (2013) 1702-1713 


\section{Figures}

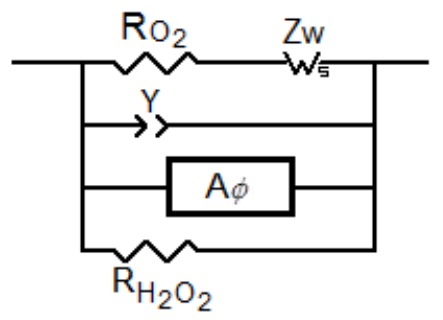

Figure 1. Electrical circuit representing electrochemical mechanisms in the ORR reaction with hydrogen peroxide formation

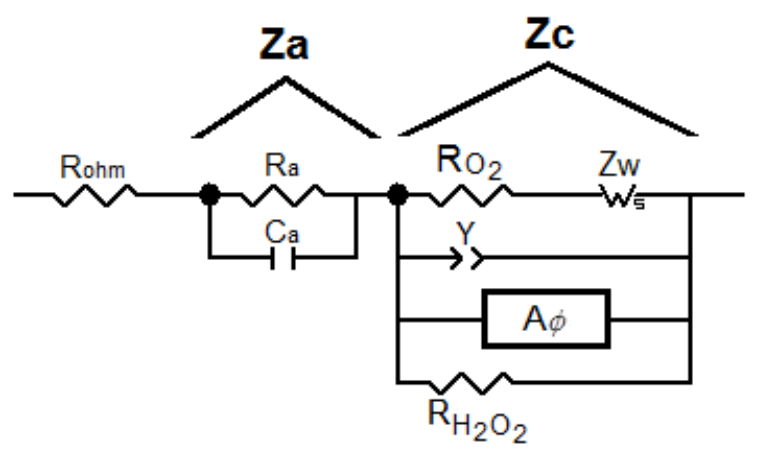

Figure 2. Electrical circuit representing the PEFC
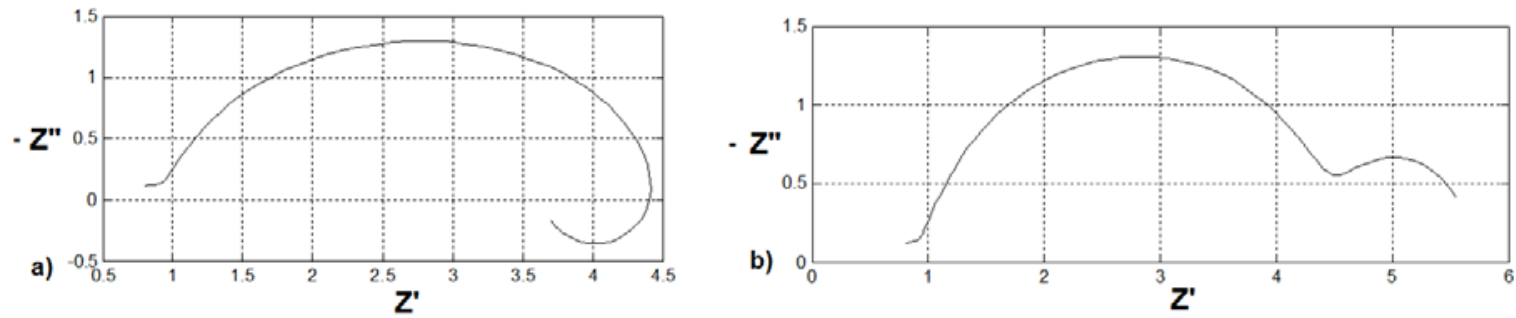

Figure 3. Effect of charge transfer resistance of hydrogen peroxide reaction on impedance spectrum, a) $R_{\mathrm{H}_{2} \mathrm{O}_{2}}>$ $R_{\mathrm{O}_{2}}+Z_{W}$, b) $R_{\mathrm{H}_{2} \mathrm{O}_{2}}<R_{\mathrm{O}_{2}}+Z_{W}$ 


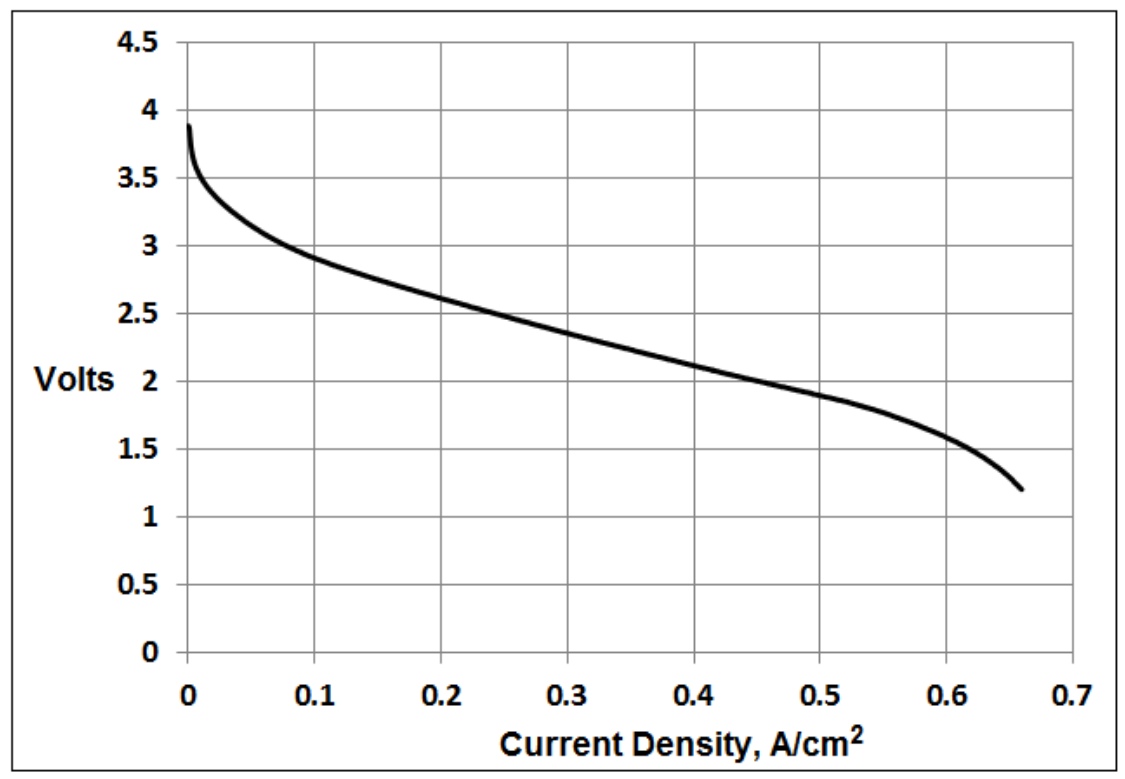

Figure 4 Polarisation curve for open-cathode stack
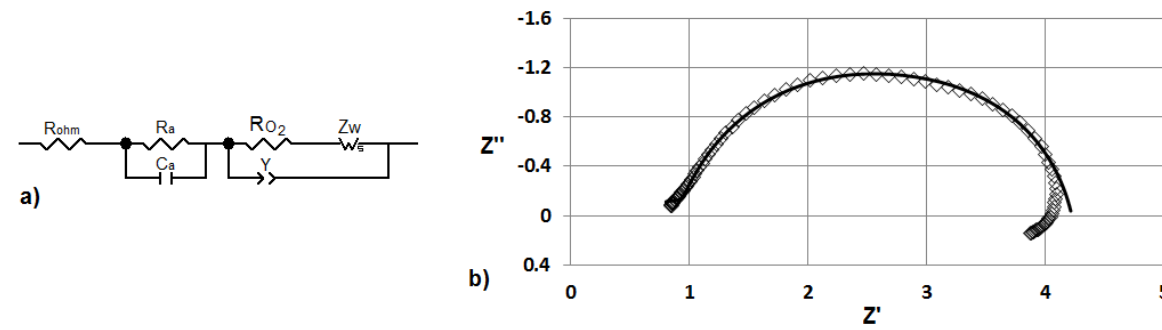

Experimental $0.3125 \mathrm{~A} / \mathrm{cm}^{2}$

Zview fitting

Randles circuit

Fig. 5 Comparison between experimental and simulated data, a) Randles circuit, b) fitting result

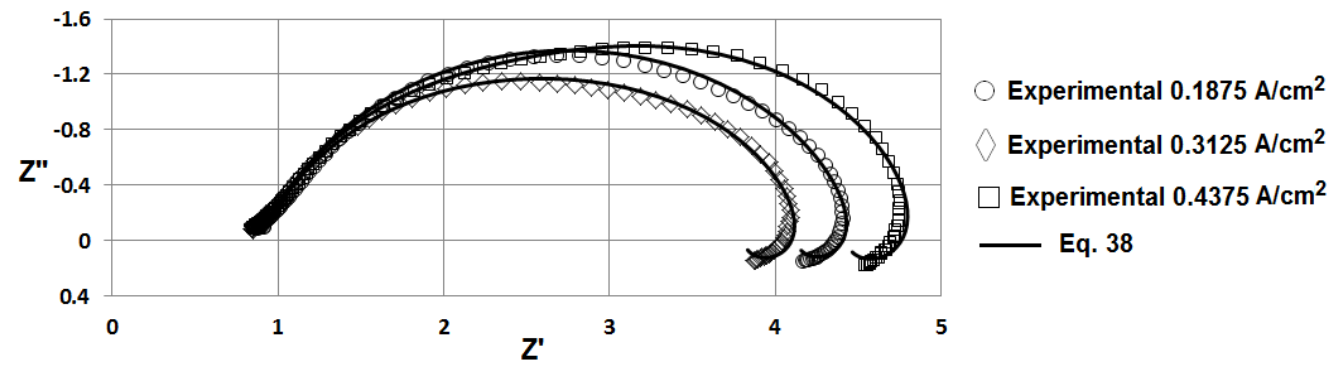

Figure 6. Comparison between experimental and simulated data from Eq. 38 


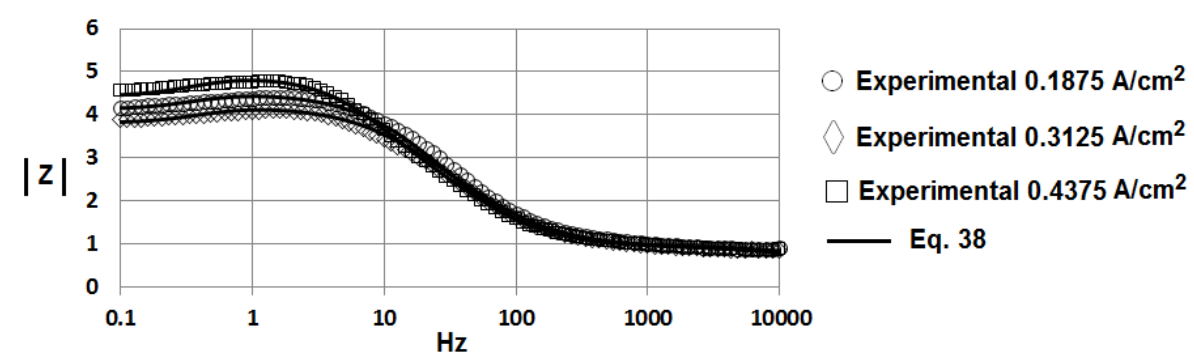

Figure 7. Comparison in Bode format (modulus) between measured and simulated data

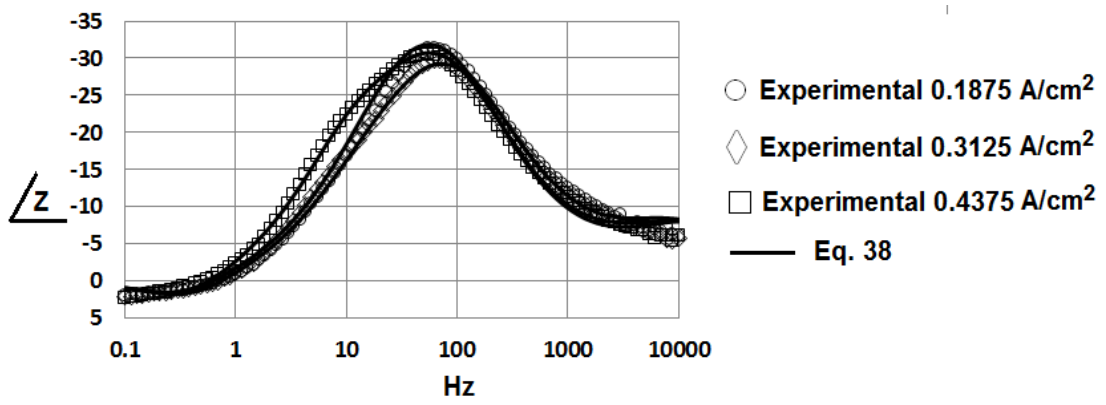

Figure 8. Comparison in Bode format (phase) between measured and simulated data 